\title{
Brecht en Shaffer: una revisión
}

\section{Lucas Gagliardi}

Universidad Nacional de La Plata, Argentina

lucas.lenguayliteratura@hotmail.com.ar

Fecha de recepción: 31/05/2020. Fecha de aceptación: 30/07/2020

\begin{abstract}
Resumen
En este trabajo se analiza la presencia de elementos de la poética brechtiana en el teatro del autor británico Peter Shaffer. Un sector de la crítica ha postulado que las principales obras de Shaffer se encuentran profundamente influidas por la poética teatral de Bertold Brecht; esto se advertiría especialmente en el repertorio de técnicas del alemán que son utilizadas por el británico. Un sector minoritario de la crítica incluye la obra de Shaffer dentro de dentro de otras tradiciones como el drama poético, el teatro de la crueldad y el existencialismo. El objetivo de esta investigación es revisar los alcances de la poética de Brecht en torno el teatro shafferiano. Esto implica polemizar con el modo en que se suelen pensar las influencias en el campo de la producción artística así como en el modo en que ha sido leída la poética de Brecht y adjudicada a otros dramaturgos.
\end{abstract}

Palabras clave: Brecht, Shaffer, teatro comparado, técnica dramática, distanciamiento.

\section{Brecht in Shaffer: a Revision}

\begin{abstract}
In this article we study te presence of Brecht's poetics in Peter Shaffer's work. Some critics have stated that this British author is deeply influenced by Brechtian theatrical poetics, given his use of a repertory of the German playwright's techniques. A few other critics argue instead that Shaffer's production is better understood in the light of some other traditions, such as poetic drama, theatre of cruelty and existencialism. The aim of this study is to revise the contact between Brecht and Shaffer. This implies questioning the way in which influences are usually thought of and the way in which Brecht's theory has been attributed to several dramatists.
\end{abstract}


El espectador que se sienta en la butaca de una sala teatral para ver Equus, de Peter Shaffer presenciará el momento en que el protagonista deja ciegos a siete caballos. Los equinos no son animales auténticos que han sido conducidos al escenario, sino bailarines. El espectador los puede distinguir con facilidad bajo unas máscaras equinas tejidas con alambre que dejan traslucir el rostro humano. Ese mismo espectador, con sólo girar un poco la cabeza, verá a todo el elenco sentado a un costado de la escena sin participar de la diégesis. Ante una propuesta de este tipo, altamente pautada por las indicaciones del guión teatral, parece sencillo pensar en las influencias de la poética brechtiana desde el minuto uno. Buena parte de la crítica acerca de Shaffer, de hecho, lo ha colocado en el radio de flujo del dramaturgo alemán.

Esta filiación, a la vez que nos habla sobre el teatro de Shaffer, nos dice algo acerca del modo en que la teoría y poética de Brecht suele ser leída: como un conjunto de técnicas que producen el famoso distanciamiento. Esta forma de proceder suele descuidar la unión entre forma y significado con la consecuencia de que la identificación de las técnicas brechtianas en otros autores contemporáneos o posteriores será interpretada en términos de influjo y parentesco sin mayores miramientos.

Nuestro objetivo es revisar los alcances de la poética brechtiana en el teatro de Peter Shaffer. Sostenemos que esta identificación resulta algo apresurada, cuando no superficial, pues si bien la producción del dramaturgo inglés posee elementos en común con los del alemán, difiere la base ideológico-filosófica que sustenta esas elecciones formales. En lugar de pensar en términos de influencias claras y algo mecánicas sostenemos que el teatro de Shaffer absorbe técnicas, tendencias y temáticas y las reconfigura bajo su propia teoría del drama y el hecho teatral.

\section{El estudio de las influencias}

El establecimiento de influencias entre un artista y otros es siempre un territorio espinoso aunque también necesario muchas veces para la tarea del crítico que investiga una disciplina artística.

El estudio de las influencias posee una larga historia. Podemos señalar que fue sistematizado por primera vez en el campo de los estudios literario a través de la filología y la literatura comparada. El concepto vertebrador de los estudios sobre la influencia era el de «fuente», es decir, un antecedente textual que se identifica en el texto derivado. Roland Barthes fue el teórico que separó el concepto de fuentes y lo reemplazó por el más dinámico de intertextualidad. Esto se dio en el contexto la difusión de las teorías de Mijaíl Bajtín en Francia (Marchese y Forradelas, 2013: 185). La cuestión de los antecedentes conllevaba varios problemas. Por un lado, como señalan Marchese y Forradelas (2013: 184), "Los antecedentes se estudiaban sobre todo desde un punto de vista temático"; es decir que había poco lugar para la consideración de otros aspectos que incidieran en la relación de influencia. Por otro lado, el modelo explicativo se reducía a un esquema de relaciones entre A y B con cierto mecanicismo (Vega y Carbonel, 1998: 47-48). Sumada a cierta mirada inmanentista sobre el texto, los estudios filológicos y comparatistas veían las relaciones entre obras y autores en términos de parentescos sin mayores problematizaciones en cuanto a la intertextualidad o a las posibles adhesiones y distanciamientos de un autor para con otros textos y poéticas. Posteriormente, los estudios comparatistas y, sobre todo, los de teatro comparado (Dubatti, 2003) ampliaron el rango analítico para pensar también en otros aspectos expresivos y más específicos del teatro frente a la literatura y otras expresiones artísticas. Otra teoría que vale destacar, también surgida de los estudios literarios y de amplia difusión sobre el tema, es la de Harold Bloom (1973) acerca de la angustia de las influencias. Esta se sustenta en una mirada sobre la intertextualidad 
(ya no sobre las fuentes de los estudios precedentes) y el aspecto psicológico de los procesos creativos. Bloom puso su atención sobre la conflictiva relación entre un escritor y sus predecesores, su necesidad de identificarse o distanciarse respecto de estos últimos. La teoría de Bloom, si bien fue pensada para el caso de la poesía, permite incluir dentro del estudio de las influencias no solo a las obras en sí, sino también a las ideas que conforman la poética de un autor, en el sentido de conjunto de elecciones compositivas, temáticas, expresivas (Marchese y Forradelas, 2013:324) y asunciones acerca de la tarea creativa.

Los estudios de la crítica genética -ya no solo literarios sino ampliados a otros campos que involucran la escritura y textualidad- permitieron delimitar metodológicamente con mayor pericia el territorio por transitar a la hora de pensar cuestiones como la influencia. Esta puede identificarse en momentos de la "génesis escritural» (Lois, 2001) de una obra, dejando de lado la mera «crítica de fuentes» para concentrarse en los procesos de endogénesis y exogénesis que muestran la apropiación y modificación en la escritura (Ferrer, 2007; Lois, 2001: 20). La crítica genética, en especial la de corte sociocrítico, se opone a la distinción entre fuente y obra (36) en tanto observa una continuidad de discursividad social entre ambas. En todo caso, el objetivo del genetista es encontrar evidencia de la aparición de determinado discurso social en la escritura y las relaciones que se establecen con el mismo (polémica, acuerdo, etc). Mientras que los estudios tradicionales sobre el texto literario (y el guión teatral, en este caso) solo toman la versión édita o publicada y buscan identificar en su superficie guiños, referencias y elecciones estilísticas, la crítica genética considera posible reconstruir la poética y las relaciones entre autores en documentos como anotaciones metaescriturales, marginalia, pretextos redaccionales que se suman a los éditos. ${ }^{1}$ Esta ampliación de las posibilidades heurísticas permite considerar con el mismo estatuto a lo que habitualmente se llama «texto» (de la obra) y al conjunto de epitextos (Lois, 2001:155) que lo rodean, como las notas del autor, prólogos, prefacios, declaraciones en medios periodísticos, etc.

Desde un punto de vista metodológico, nuestro recorte toma esa consideración amplia de los documentos que nos permiten estudiar el problema de investigación. No se trata de un estudio genético en tanto no se confrontan diferentes estadios escriturales (solo trabajaremos con guiones teatrales y escritos programáticos y explicativos de ambos autores y la reconstrucción del interdiscurso). Sin embargo, prestaremos atención tanto a la historización como a la reelaboración que se produce en la producción de Shaffer frente a la de Brecht. Al igual que las investigaciones genéticas en torno al teatro, seguimos la diferenciación entre estudios sobre el quión teatral y el hecho o representación teatral que involucra el convivio y que también podría ser analizado en términos de génesis (Dubatti, 2008; Gagliardi, 2016).

\section{Brecht por doquier}

El crítico literario Frederic Jameson dijo alguna vez que no existe un único Brecht, sino una pluralidad de Brechts: el dramaturgo, el poeta, el activista (2013: 19). Siguiendo esta afirmación, podemos decir también que no existe sólo un modo de rastrear los derroteros de su programa estético en los dramaturgos contemporáneos y posteriores. Como hemos dicho con anterioridad, una de las vías más frecuentes para encarar un análisis de influencias consiste en identificar en un autor determinado un conjunto de elementos que pertenecerían a un hipotético repertorio

1 Tomo un ejemplo de este postulado en relación con Manuel Puig. Amícola (2004: 12) interpreta una anotación metaescritural del escritor en la cual se dice a sí mismo "Evitar la cortazareada». En esa anotación, Amícola reconstruye una serie de elecciones que conforman la poética puigueana frente a la de Cortázar. La relación de polémica aquí se concentra en el rechazo de Puig por el golpe de efecto que encuentra en la literatura de su contemporáneo. 
brechtiano. En un estudio comparativo tradicional, esos elementos serían temáticos; en estudios de teatro comparado, incluirían también conjuntos de técnicas (Dubatti, 2003).

Para este análisis, es necesario revisar cual sería ese repertorio y su relación con la poética brechtiana. Recordemos que entendemos poética en un sentido que incluye tanto el programa estético-ideológico al igual que un conjunto de elecciones plasmadas efectivamente en obras. La base del teatro propuesto por el alemán se encuentra en su postura de confrontación frente al efecto de catarsis y al compromiso afectivo del espectador con la obra. Estos rasgos se encuentran presentes para Brecht en el teatro que sigue los lineamientos de la teoría aristotélica expresada en la Poética (Rodrigo Burón, 2013: 139; Jameson, 2013; Ílter, 2006; Gaspar, 2003: 3-24). Frente a aquella tradición, Brecht opuso una concepción nueva que acentúa en el raciocinio del espectador ante el espectáculo, una idea que busca generar distancia crítica y conciencia frente al artificio (Wamba, 2013: 1; Rodrigo Burón, 2013: 145). Este es el fundamento del teatro épico o no aristotélico en las formulaciones de Brecht que se recoge en su libro Escritos sobre el teatro (2009). Uno de los conceptos fundamentales para esta teoría y práctica es el efecto diametralmente opuesto a la catarsis aristotélica: el distanciamiento o extrañamiento (verfemdunseffekt). Según afirmaba Castagnino en 1969 (p. 33), este concepto no sería una propuesta enteramente original de Brecht sino que encontraría sus raíces en formulaciones de San Agustín y Diderot. Este señalamiento no es novedoso para los estudiosos de la obra de Brecht puesto que este último hizo un racconto de obras de diferentes épocas y autores para fundamentar su propuesta: reconoció la influencia del teatro noh japonés y de Shakespeare, por citar ejemplos. Por su parte, Jameson (2013: 64) emparenta el concepto del distanciamiento con el de la ostranenie del formalismo ruso. En una dimensión histórica, Dulcinea Rodrigo Burón (2013: 139) también traza las coordenadas filiatorias de esta formulación y su oposición a algunas formas de vanguardia: "[El teatro épico] También enfrentará la forma estética del gesto expresionista -vacío de contenido- con la materialización física del espacio escénico, que hace una referencia objetiva a la realidad del mundo por medio de su descripción del gesto épico. Otros elementos vanguardistas - como la fragmentación, la interrupción, la narratividad escénica de la escenografía - van a servir al autor para definir el concepto de montaje escénico como una nueva categoría estética".

El término Verfemdunseffekt refiere a la toma de conciencia del espectador frente al artificio del espectáculo teatral. Por medio de los recursos de la dramaturgia, el auditorio podría evitar la compenetración emotiva con los personajes y su historia para lograr una toma de distancia crítica, es decir, racional. Este teatro «no combate las emociones sino que las examina y no duda en producirlas. El teatro convencional se hace culpable de la separación de razón y sentimiento eliminando prácticamente la razón» (Brecht citado en Wamba, 2013: 4).

Esa toma de conciencia a través de la obra artística era necesaria para el cambio sociopolítico a través de la liberación de las conciencias (Rodrigo Burón, 2013: 139-140) en el programa ideológico-estético de Brecht, por lo cual vemos en ella la reintroducción de la idea del teatro como ámbito experimental y didáctico. Jameson afirma que en Brecht se repliegan al menos dos términos de la famosa tríada de Cicerón (docere, delectare et movere o enseñar, deleitar y conmover). "Enseñar recupera el parentesco con el mandamiento de deleitar y la función didáctica de la pieza" (Jameson, 2013: 15). A su vez, la función de conmover es puesta en crisis por Brecht, cuando discurre sobre la necesidad de poner límite a la catarsis del espectador, al menos en sus primeras formulaciones.

Como vemos, la propuesta incluye dentro de lo estético a lo político y didáctico. El teatro épico brechtiano no es sólo una cuestión de forma; de ahí la crítica de Brecht 
al expresionismo que consideraba vacío. Esto constituye un nudo por desenmarañar para el análisis comparado, ya que usualmente se repara en técnicas distanciadoras como el uso de los carteles (Merkmale, que marcan los episodios de la obra) así como en las canciones, los coros, la danza o en un tipo específico de marcación actoral alejada del naturalismo sin prestar atención debidamente al objetivo político de la propuesta brechtiana. Cabe recordar que Brecht establece que el actor «no debe hipnotizar al público, tampoco tiene que hipnotizarse a sí mismo. No debe recitar con los músculos tensos: un gesto hecho con los músculos tensos, por ejemplo, arrastra mágicamente las miradas y hasta las cabezas de los espectadores [...]. La dicción del actor debe librarse de las cantinelas litúrgicas y de esas cadencias que tienen la virtud de acunar al oyente» (Brecht, en Castagnino, 1969:35). En cuanto al objetivo político, el rastreo de sucesores suele incurrir en la negligencia de ignorar la política de las formas y las ideas presentes en las poéticas de los supuestos neobrechtianos.

En importante recordar que muchas de estas formulaciones teóricas son conocidas por numerosos dramaturgos en Europa a partir de Escritos sobre el teatro, volumen que se publicó hacia la década de 1960, es decir, ya avanzada la producción escénica del alemán. Jameson (2013:21) sostiene que en dichos textos se domestican sus prácticas e ideas iniciales a medida que se le da forma a la teoría: por ejemplo, la forma dramática conocida como Lehrstrucke (experimental y lúdica) de alguna de sus primeras piezas queda subsumida por la formulación del teatro épico en las revisiones del escritor. Esto constituye una práctica de reescritura (Lois, 2001), donde Brecht se reafirma como autor de una teoría a la vez que de un conjunto de piezas teatrales.

Buena parte de la crítica identifica lo brechtiano en otros dramaturgos a partir de las formulaciones de Escritos sobre el teatro. Sin embargo, en una reconstrucción histórica por medio de testimonios y fuentes no resulta extraño encontrar testimonios de que muchos de los dramaturgos contemporáneos a Brecht tuvieron un contacto directo con las obras del alemán antes que con la teoría ya sistematizada. Esto constituye una dificultad metodológica habitual para el comparatismo teatral y muy especialmente en el caso británico pues hasta la llegada de la compañía Berliner Ensemble a Inglaterra (en 1956), las obras del alemán eran poco conocidas, en especial a raíz de la diferencia idiomática. Se puede reconstruir el clima que rodea al estreno de Madre Coraje con la Berliner Ensemble en Londres por medio de las notas periodísticas de diarios como The Guardian (The Guardian, 1956). El grueso del ideario brechtiano se encontraba mucho menos divulgado en el ámbito teatral y, cuando mucho, se lo reducía a la identificación de Brecht con el comunismo (Innes, 2002).

¿Cuáles son las consecuencias de este tipo de contacto entre un autor y otros? La primera es casi una obviedad: tomar técnicas e ideas de otro artista -ya sea en forma consciente o inconsciente- no implica adherir por completo a su programa político y filosófico. En segundo lugar, cuando el contacto se produce por medio de performances específicas de sus obras, sin la guía de lectura que supone la formulación teórica ya articulada o el guión teatral, las apropiaciones pueden mostrarse mucho más diferenciadas entre sí. El público y los artistas del ámbito escénico pueden comprender de modos muy diferentes las posibilidades del efecto distanciador, por ejemplo. No debemos perder de vista que la difusión de las obras brechtianas en Inglaterra se produce en conjunto con la de otras corrientes escénicas, como el teatro del absurdo con su base filosófica existencialista o las ideas de Antonin Artaud. Algunas de estas nuevas sensibilidades comparten técnicas con el repertorio brechtiano, dificultando la posibilidad de establecer parentescos claros a partir de un análisis meramente formal.

Debemos pasar entonces de la idea de un «Brecht por doquier» en el teatro británico de posguerra a matizar las coordenadas que la crítica (Esslin, 1966; Reinelt, 1996) 
ha trazado. Peter Shaffer, el dramaturgo que nos ocupa, participa de cierto radio de influencia, pero debemos revisar los alcances de la misma evitando el inventario superficial de elementos que probarían un parentesco.

\section{Brecht en Inglaterra: el teatro de posguerra}

El período de posguerra en el teatro inglés estuvo marcado por el surgimiento de nuevas voces que disputaron la preponderancia de montajes del repertorio clásico integrado por piezas de William Shakespeare, Bernard Shaw y Oscar Wilde. No existía una inquina específicamente contra estos autores, sino contra la práctica teatral de los montajes respetuosos y pulcros (well-made plays) centrada en dicho repertorio, así como cierta crítica señalaba la falta de temáticas más relacionadas con la realidad social contemporánea.

Un autor clave en este contexto fue John Osborne, conocido principalmente por Look Back in Anger (1956), quien ha sido señalado como el despuntar del movimiento denominado Angry Young Men, recurrente modelo de artista (y personaje) que se muestra preocupado por la situación de las clases trabajadoras (Gaspar, 2003: 88). Este teatro -de corte político. en mayor o menor medida- entró en disputa con la tradición de producciones con temáticas que remitían a épocas pasadas. Las piezas de este movimiento teatral (New Drama) instauraron en el circuito comercial del West End (ubicado en el oeste de Londres, una de las zonas más acaudaladas) otras posibilidades temáticas y expresivas. Ese mismo año, el Berliner Ensemble estrenó una obra en Londres y generó un gran impacto en el ambiente. Algunos críticos como Michael Billington (2013) señalan como punto de quiebre este primer montaje de la compañía alemana. Incluso postula este episodio como el disparador para la creación del National Theatre en 1963. Esta institución sería uno de los principales reductos de obras con gran despliegue técnico y temáticas también muy variadas, entre las cuales se nota el toque brechtiano en la dirección.

Ahora bien, como sostiene George Wellwarth (1966: 270), la trayectoria de Osborne y otros autores como Arnold Wesker-inicialmente ligados a un realismo social (kitchen sink realism)- incorporaron progresivamente parte de la propuesta brechtiana por medio de recursos como los del musical (siguiendo el modelo de la Ópera de los dos centavos) o el carácter episódico del teatro épico en general (Wellwarth, 1966: 275, Innes, 2002: 7). En efecto, Wellwarth señala que la pieza Lutero sería la más brechtiana en el repertorio de Osborne: tanto su temática histórica y técnicas empleadas -como, por ejemplo, el uso de las banderas a modo de carteles que marcan los episodiosresponden a las tendencias marcadas por el alemán por aquella época y a intenciones similares (1966: 279). Existe otra porción de los dramaturgos como Robert Bolt, Christopher Hamptom, Edward Bond, John Arden y David Hare (Innes, 2002: 115; McLane-Iles e Iles, 2007: 413), cuya adherencia a la poética brechtiana fue rotunda, pues compartían plenamente el sustento ideológico-filosófico del alemán. En particular, Christopher Innes (2002: 9) señala que, dentro del drama británico, la propuesta del teatro épico fue vista no tanto como una oposición completa respecto del naturalismo de Ibsen o Shaw, sino como una forma alternativa de retratar la sociedad en términos políticos. De ahí que la franja de autores del llamado kitchen sink realism de los años 50 incorporaran paulatinamente algunas técnicas brechtianas. Podemos decir entonces que, en el teatro de la época, se va produciendo una tensión entre realismo y extrañamiento, cuyo fuego ya había sido encendido por Samuel Beckett en 1955 con Esperando a Godoty fue alimentado luego por la temporada del Berliner Ensemble en Londres. Al respecto, Innes (2002: 113) destaca que ya en 1930 se había llevado a los escenarios ingleses un montaje de Los siete pecados mortales de la burguesía; sin embargo, el contacto más fuerte con Brecht se da a partir de Madre Coraje. 
El estreno de Madre Coraje en 1956 no tuvo un gran recibimiento por parte de la crítica (Innes, 2002: 7; Gaspar, 2003: 84), pero la presencia de estas obras durante la temporada generó impacto en las prácticas escénicas; el más claro se verificó en la conformación de compañías teatrales como la Royal Shakespeare Company, que seguía el modelo de la compañía permanente tomado del Berliner Ensemble (Olsom, 1988: 123). Además de los ecos en jóvenes escritores, muchos directores importantes del período como John Dexter y Peter Hall (directores de varias obras de Peter Shaffer) tomaron las ideas y técnicas brechtianas para montar obras de Shakespeare y otros autores clásicos con una renovada estética. La cuestión idiomática produjo que el impacto de Brecht se sintiera más a nivel del montaje que de las ideas presentes en el guión teatral. (Esslin, 2000: 147 y 148).

¿Dónde ubicamos a Shaffer dentro de este panorama? Sus primeras obras, Five Finger Exercise (1958) y el doblete The Private Eye, The Public Ear (1962), fueron textos de dramaturgia clásica y realistas, como las primeras obras del mencionado Osborne, pero sin el mismo interés por el realismo social. A partir de la década del 60 se produjo un viraje dentro de la producción de Shaffer. El National Theatre se fundó en esos años y buscó disputar el lugar predominante al circuito del West End. La nueva institución buscó la incorporación de nuevas obras que resultaran convocantes, provocativas y, a la vez, de una gran realización escénica. Shaffer fue uno de los principales baluartes de esta política cultural en los teatros oficiales. En 1963, estrenó The Royal Hunt of the Sun, obra que se basaba en una temática histórica (la conquista de Perú) y mostraba un conjunto de técnicas escénicas que resultan impactantes para el público de la época.

A partir de entonces, la crítica en torno a Shaffer (Ílter, 2006; McLane-Iles e Iles, 2007; Mahdi, 2014; Plunka, 1988; Reinelt, 1996; Rosenthal, 2013) comenzó a identificar las obras trágicas del autor con el teatro épico. En el siguiente fragmento de Ílter podemos ver la construcción crítica que pone en correlación la poética brechtiana con las obras del dramaturgo a partir de ciertas omisiones:

[...] although the audience is involved emotionally in the play as the themes have a psychological nature, Shaffer puts a limit to the emotional empathy of the audience with the literary work, for he holds that the audience should be able to analyze, question and understand the meaning beyond the dramatic action. (2006:2)

Dicha interpretación acerca del aspecto emotivo minimiza este componente en la obra de Shaffer, lo que permite una mayor identificación con la teoría del teatro épico. Sin embargo, viene a contrapelo del hecho de que las tragedias shafferianas tienen un gran peso en el pathos, el melodrama y que el propio autor reniega de la tesis brechtiana.

\section{Shaffer, un sucesor inconforme}

Un rápido vistazo a la producción shafferiana pone en evidencia la posible huella de Brecht sobre las diferentes técnicas escénicas y formas dramáticas empleadas (McMurraugh-Kavanagh, 1998; Ílter, 2006), a la vez que la dificultad de homologación entre las poéticas de ambos dramaturgos. Tomemos las múltiples notas de Shaffer para la representación de Royal Hunt of the Sun (1963), Equus (1973), Amadeus (1979), sus obras trágicas más conocidas. Shaffer realiza un pautado muy específico sobre la representación de cada obra, al igual que en muchos textos del alemán. Se podría decir que ambos dramaturgos muestran en su escritura una preocupación por el uso de la forma y los dispositivos para generar efectos específicos. Desde el geneticismo se entiende este gesto escritural como la instauración de su presencia autoral o firma (Derrida, 1971) para direccionar la semiosis en torno al guión teatral. Ambos acompañan las ediciones de sus textos con un aparato epitextual considerable para guiar las 
puestas en escena, aunque estas no necesariamente sean respetadas al pie de la letra por los diferentes directores, como en el caso de la Ópera de los dos centavos (1957). En esto observamos una clara diferencia entre ambos dramaturgos y las tendencias posteriores como el teatro posdramático frente a la edición del guión teatral.

En una de las didascalias de Royal Hunt of the Sun, Shaffer indica de forma breve y desprovista de detalles "The men climb the Andes" (Shaffer, 1963: 29) para mostrar el ascenso de los soldados españoles por las montañas de los dominios incaicos. En las notas de representación que acompañan la versión édita del texto sostiene que la acción debe representarse por medio de una austera escenografía que interactúa con la pantomima de los intérpretes y la coreografía. El interés explícito por reunir la danza, la pantomima, la música tribal y las máscaras obedece a la idea de un espectáculo teatral total que escape a la detracción que supone la ilusión realista en la representación de estos hechos. Aquí se vislumbra una idea de la poética teatral shafferiana donde, como en Brecht, hay un alejamiento deliberado del naturalismo, pero cuya las intenciones y efectos buscados no son los mismos. Shaffer declara sobre Royal Hunt: "It represents the sort of theatre I have long dreamed of creating, involving not only words but also mimes, masks, and magics» (1963).

En el caso de Equus también encontramos estrategias anti-miméticas y distanciadoras en las indicaciones de Shaffer. Allí se establece que los caballos a los que ciega Alan Strang, el protagonista, deben ser representados específicamente por hombres y poner en evidencia el artificio:

\begin{abstract}
Any literalism which could suggest the cosy familiarity of a domestic animal-or worse, a pantomime horse-should be avoided. The actors should never crouch on all fours, or even bend forward. They must always-except on the one occasion where Nugget is ridden-stand upright, as if the body of the horse extended invisibly behind them. Animal effect must be created entirely mimetically, through the use of legs, knees, neck, face, and the turn of the head which can move the mask above it through all the gestures of equine wariness and pride (Shaffer, 1974: 15)
\end{abstract}

El espectador debe ser consciente de la presencia de actores, quienes podrían recurrir, como máximo, a algunos gestos, pero no a una completa pantomima de los caballos. Las técnicas de representación indicadas por el dramaturgo ponen en tensión el subtexto zoofílico y tabú de la obra con la mostración de ese artificio. Si vemos este hecho en el marco de la dramaturgia brechtiana, podemos interpretar que se busca generar cierta distancia en el espectador frente a los significados potenciales de la obra (Innes, 2002: 488). El caballo es el objeto de deseo de Alan, pero también es cierto que este signo representa, además de lo sexual, una serie de ideas más abstractas como el malestar existencial que expresa la escritura de Shaffer en sus obras de índole trágica (Dubatti, 2013).

En esta misma pieza, por otra parte, se puntualiza que los actores deben permanecer en escena sentados en algunos elementos del despojado escenario (Shaffer, 1974: 13), como mencionamos al principio de este trabajo. Los personajes deben funcionar al modo del coro de la tragedia griega (Innes, 2002: 483) y articular el sonido que identifica a Equus, la presencia espiritual que da título a la obra. Al momento de entrar a escena, los personajes deben dirigirse al centro y tomar la palabra. El texto superpone constantemente líneas temporales (narración a cargo del psiquiatra y lo narrado que se encuentra en los testimonios del paciente). Sumando esto a la organización espacial de la obra se genera una tensión entre el espacio público y privado, entre el espacio diegético y extradiegético y, por qué no, entre escenario propiamente dicho, bambalinas y auditorio en una obvia ruptura de la cuarta pared. A esto debe sumarse que la primera puesta de Equus se llevó a cabo en una sala bastante particular del Old Vic (parte del 
mencionado National Theatre), el cual no seguía la disposición tradicional del teatro a la italiana. El escenario en cuestión es circular y está ubicado cerca del centro de la sala, por lo cual los asientos del público lo rodean en varias direcciones. Esto permite que se vuelven aún más difusos los límites entre el auditorio y el espacio escénico.

Podemos pensar en otra recurrencia formal brechtiana presente en Shaffer: el personaje-narrador. Este recurso se relaciona fuertemente con la alternativa al teatro aristotélico que proponen las formulaciones del autor. El término épico es entendido por Brecht en el sentido aristotélico de la Poética, es decir, como una narración. Si bien Shaffer no lleva hasta las últimas consecuencias lo épico (por ejemplo, en cuanto a la marcación actoral y la interpretación en tercera persona), sí adopta la presencia del personaje que conduce la pieza teatral como si se tratara de un relato de hechos ocurridos hace mucho tiempo. Si bien esta es la acepción de épico tomada por Brecht, algunos críticos han señalado que su concepción de lo épico puede relacionarse con lo que postula Bajtín para la épica-epopeya: un relato en verso cuya temporalidad se concibe profundamente separada de la del receptor. Esto explicaría la recurrente elección de Brecht de hechos históricos y ambientes lejanos con respecto al espectador del siglo XX. Ílter explica el alcance del término «épico» para la teoría bretchtiana: "In this respect, Bakhtin's elucidation of epic contributes to the understanding of Brecht's use of the term 'epic'. Making use of the past narratives, Brecht creates an imaginary, past, unattainable epic world which cannot be reached by the audience and thus impossible to identify with" (2006: 11). En Brecht, este recurso puede encontrarse en El alma buena de Se-Chuán o La resistible ascensión de Arturo Ui, donde los prólogos y epílogos presentan un personaje que se dirige a la audiencia para invitarlos a presenciar una historia; en las obras mencionadas de Shaffer encontramos un planteo muy similar.

Royal Hunt of the Sun es narrada por un adulto y desilusionado Martín Soto, así como Equus es el relato del psiquiatra sobre un caso clínico crucial en su carrera. Por otro lado, en Amadeus se elige a un Salieri ya anciano, quien no solo da la bienvenida al público -al que invoca específicamente para relatar su versión de los hechos- sino que se equipara con ellos hacia el final: Salieri, tras su fracasado intento de suicidio, se reconoce como «Patron Saint of Mediocrities» (Shaffer, 2001: 117) e identifica a los mediocres a su alrededor, extendiendo sus brazos para alcanzar al público. Este gesto -otra sacudida a la cuarta pared- es parte del juego dramático de la obra, en el cual Salieri genera identificación y a la vez distanciamiento dramático en su forma de cautivar y señalar a su auditorio (Innes, 2002: 491). Este último ejemplo nos muestra que la utilización de gestos épicos en Shaffer no concuerda del todo con la de Brecht.

Podemos analizar también la oscilación entre el minimalismo y el gran despliegue de puesta en escena que figura en las acotaciones y metatextos de Shaffer (y de los montajes más conocidos de sus piezas) y en el teatro de Brecht. En la obra de este último convergen tanto escenarios austeros como enormes y artificiosas producciones cargadas de detales que ponen en juego el artificio teatral. En Shaffer también coexisten estos usos. Así, en Equus recurre a una escenografía despojada como Madre Coraje, mientras que Royal Hunt, Amadeus y Yonadab optan por un despliegue más cercano al de Galileo, El alma buena de Se-Chuán, El círculo de tiza caucásico o incluso la Ópera de los dos centavos y La irresistible ascensión de ArthurUi. Muchos actores en escena, música constante y movimientos coreográficos artificiosos marcan todas estas obras.

Otro aspecto al que podríamos referirnos es al uso de la temporalidad dentro del repertorio shafferiano en relación con el mencionado teatro épico. Brecht recomendaba marcar el discurrir de la obra teatral con títulos y carteles a modo de separadores de episodios, incluso anticipando la resolución de las escenas. En Amadeus no tenemos estos elementos visuales: cabe desatacar que, si bien no existen carteles que marquen el cambio de escena o anticipen lo que ocurrirá, la mediación del personaje narrador 
(Salieri) absorbe esa función anticipando en sus parlamentos el devenir de las acciones. A su vez, conocemos el destino de Mozart y su muerte de antemano, hecho con el que Shaffer juega constantemente. Encontramos, en cambio, algunas marcaciones de las diferentes escenas mediante la narración de Salieri o el ingreso y salida de los venticelli, dos sirvientes que hablan generando rimas y que parecen provenir de una tradición del personaje cómico del vaudevil. El transcurso del tiempo también afecta la caracterización del compositor italiano: Salieri oscila entre la avanzada edad de su situación como narrador -tiempo de la enunciación, podríamos decir- y el de sus recuerdos -tiempo del enunciado-. La diferencia no está marcada por trucos de maquillaje realistas, sino por cambios en la proyección de las luces sobre el actor. Por otro lado, la recurrencia en la producción shafferiana por representar historias situadas en tiempos alejados de la situación del espectador del siglo XX también puede ponerse en relación con la propuesta de Brecht, en tanto ese alejamiento ayudaría a interrumpir la identificación inmediata sumado al carácter episódico del teatro épico. Enfatizamos la palabra ayudaría en tanto la recepción de la obra siempre rebasa las intenciones del dramaturgo. Nos basta un ejemplo del propio Brecht para observar este hecho: el dramaturgo alemán manifestó su descontento frente a la reacción emotiva y conmovida del público que asistió a las primeras funciones de Madre Coraje.

Hasta aquí enumeramos y detallamos una serie de coincidencias formales en los dispositivos de Shaffer y Brecht, pero como se advierte en dicho recuento, surgen notables desajustes que se advierten con solo mirar los guiones teatrales. Si recurrimos a los epitextos, encontraremos declaraciones explícitas de Shaffer y su posición frente a la influencia brechtiana: «I hate it when Brecht says that we should not be interested in the next scene because it distracts us from the current one. I find that priggish and tedious" (Shaffer, 1963: Xx). El teatro shafferiano no parece plantearse un distanciamiento meramente racional e intelectual, al menos como lo proponían las formulaciones más conocidas de Brecht (MacMurraugh-Kavanagh, 1998: 3); tampoco resulta sencillo determinar que los dispositivos y notaciones dramáticas apunten la toma de conciencia como condición para un cambio de orden político-social ni que provengan exclusivamente del influjo del autor alemán.

Como hemos dicho, la base de la teoría dramática del alemán está en la suspensión o limitación de la identificación catártica entre el público y el personaje. En Shaffer, si bien existe la necesidad de generar momentos de distancia analítica, no hay intenciones de suprimir la empatía con los personajes y dicha actitud no tiene como objetivo la reflexión sobre aspectos sociopolíticos, económicos o de clase sino trascendentales (Ílter, 2006: 12). La negativa de Shaffer a dejar de lado el componente emotivo se nota también en las indicaciones destinadas a los actores. Algunos trabajos de corte geneticista, como las investigaciones sobre Amadeus y sus diferentes estadios genéticos (Gagliardi, 2015; 2016), muestran la persistencia en el cambio, es decir, lo que persiste a pesar de las modificaciones. Las didascalias que brindan información sobre la risa de Mozart o la modalización en el habla de Salieri cambian en las diferentes variantes éditas, pero insisten en todos los casos en indicar el componente emotivo para el actor y el que se espera que el público reconozca. Se trata de variantes libres, cuya motivación no se puede interpretar más que a la luz del contenido y la poética del autor.

A propósito de la empatía, los personajes narradores de Shaffer intentan generar empatía en el público para que este último sea consciente del vacío existencial que Shaffer advierte y da por sentado. Conviene proponer un ejemplo comparativo para ver esta situación: en El alma buena de Se-Chuán, el narrador sale tras el cierre del telón para pedir al público que complete la obra, ya que la compañía no ha «podido encontrar un desenlace». Shaffer también se dirige al público mediante este tipo de personajes, pero no plantea interrogantes, sino afirmaciones que espera que el público reconozca. Esta postura es más frecuente en Shaffer de lo que es en Brecht, pese a que 
el teatro de este último no rehúye a la dimensión didáctica. Como señala Innes (2002: 485), la trilogía shafferiana compuesta por Royal Hunt, Equus y Amadeus presenta un planteo dialéctico, pero sus conclusiones son las de una total devastación en las que el protagonista se ve inmerso, sin dejar mucho resquicio para el análisis posterior. La función también es concientizadora, pero el mensaje está aún más preestablecido que en algunas obras de Brecht. Los personajes-narradores como Salieri, además, terminan consiguiendo la simpatía del público gracias a su ingenio y complicidad. Es cierto, no obstante, que Brecht suele recurrir a señalizaciones claras y didácticas sobre los conflictos de sus obras. Por ejemplo, el epílogo de la mencionada La resistible ascensión de Arturo Ui deja bien en claro los paralelismos para con el ascenso de Hitler en Alemania:

\author{
Lo que habéis visto estuvo a punto \\ de dominar el mundo \\ aún no hace tantos años. \\ Los pueblos terminaron por tener la razón, \\ pero nadie puede cantar victoria antes de tiempo. \\ ¡Todavía es fecundo \\ el vientre que parió el suceso inmundo! \\ Respetable público: aprendamos a ver, \\ en lugar de mirar como el cordero" (Brecht, 1964).
}

Como hemos adelantado, las obras más conocidas de Shaffer tienen como hilo conductor una pregunta existencial por la relación entre el hombre y la divinidad. En todas ellas, la relación es conflictiva y la divinidad se muestra ausente (aunque tampoco se puede decir que negada). El malestar que genera en los personajes esta situación redunda en la reafirmación del individuo frente a la sociedad: Salieri decide excluirse de la sociedad vienesa a la que rechaza por ser mediocre; Soto no encuentra eco en los valores de su época ni Dysart en su profesión, matrimonio o interacciones con otros. El yo queda desamparado y escindido, defendiéndose como último baluarte. Esto muestra una postura filosófica y política diferente a la propuesta brechtiana: el objetivo de esta última es generar en el espectador un análisis de la situación para que tome cartas en el asunto y contribuya a un cambio social en forma colectiva, no para que se quede en una reflexión y defensa de su individualidad. En Shaffer, no hay planteo de cambio colectivo y el conflicto detrás de estas obras parece estar más relacionado con un problema filosófico que con objetivos de cambio políticosocial propio de un ethos revolucionario como empresa colectiva. Fushai Lai amplía: "Shaffer's attack on social forces is not confined to any particular social system. He applies his personal vision universally, a vision which says basically that society destroys the individual by depriving him of his sense of who he is" (1989:12). En este sentido, la sensibilidad del teatro de Shaffer está más próxima al teatro del absurdo y su potencia destructiva (Dubatti, 2013).

Esta diferencia entre ambos autores reafirma nuestra afirmación inicial: la identificación entre las poéticas de ambos autores en términos de influencia de A a B resulta problemática $\mathrm{o}$, al menos, una identificación superficial que contradice algunas declaraciones explícitas de Shaffer en los epitextos de sus obras y a las propias obras.

El componente ideológico de ambos difiere sustancialmente. Aun cuando existen planeos temáticos y filosóficos similares a primera vista, dicha proximidad se muestra engañosa. Podemos decir que en ambos autores hay un cuestionamiento de la idea de divinidad, pero sus matices son distintos: en El alma buena de Se-Chuán, los dioses aparecen sólo para sostener estándares éticos puros e inalcanzables, pero no pueden intervenir en el desarrollo de los acontecimientos, en especial los económicos (Jameson, 2013: 66). En Amadeus, Royal Hunty Equus, los dioses son mencionados e invocados, 
pero no pueden aparecer en la diégesis, reforzando así la soledad de los personajes. La diferencia es que aquí el objetivo no es denunciar problemáticas socioeconómicas como las que vive Shen Te en El alma buena de Se-Chuán, sino el desengaño y hastío de los personajes. Para el teatro épico, la introspección y psicología de personajes resulta un problema:

El distanciamiento de los personajes es fundamental en este teatro, ya que la intención del teatro épico no es revelarnos el alma interna ni la psicología de los personajes, sino poner en el punto de mira del espectador las relaciones y los problemas sociales que surgen entre grupos sociales. Al espectador no se le muestran los personajes desde la introspección individualista, sino que se le muestra la estructura social en la cual son explotados, beneficiados o liberados (Gaspar, 2013: 45).

Para Brecht, las condiciones que debe generar el hecho teatral son las de una conciencia crítica y racional. Con su negación de cualquier certeza (económica, social, religiosa, científica) Shaffer dificulta esto, aun cuando sus personajes sientan envidia por los otros que sí poseen dichas certezas y no reniegan de la vida alienada en sociedad. En Equus, la conclusión del psiquiatra es que el crimen cometido por Alan Strang carece de explicación racional alguna pues no puede adjudicarla a móviles sexuales o religiosos, por ejemplo (Innes, 2002: 487). La paranoia de Salieri tampoco obtiene asidero en situaciones que el espectador pueda deducir como factores clave para evitar una caída similar a la del personaje. A su vez, los conflictos de estos personajes son eminentemente filosóficos (Dubatti, 2013).

Shaffer no ha producido una obra teórica articulada pero, como hemos visto, se pueden rescatar sus ideas y reconstruir una poética a través de sus escritos. En la mencionada nota para la representación de Royal Hunt of the Sun, Shaffer explicita su visión del teatro como una experiencia pura y específicamente escénica (1963: 4). Sin embargo, los términos en que lo hace -con la referencia a un «total theatre»-parecen ubicarlo más bien en proximidad a la obra teórica de Antonin Artaud, otro dramaturgo de notable influencia en escritores y directores de la posguerra británica. Madeleine Macmurraugh-Kavanagh (1998) sostiene que en dicho contexto se produjo también un redescubrimiento de las teorías de Artaud esbozadas en El teatro y su doble (1938). El dramaturgo francés también buscó distanciarse del anquilosamiento del naturalismo y recurrió a técnicas de mostración del artificio escénico (en especial las que toma del teatro noh y kabuki) para lograr un efecto de reflexión en el espectador al que deseaba hacer partícipe integral de la experiencia escénica. Su énfasis en el carácter ritual del teatro, su apertura a la alteridad y lo desconocido es más próximo a las preocupaciones del de Shaffer. No obstante, también en este caso, MacmurraughKavanagh (1998: 27) señala que el británico sería un discípulo díscolo pues ignora el desdén de Artaud por el aspecto psicológico de los personajes. Lo que tenemos en Shaffer es, lisa y llanamente, una poética propia que se configura por constantes temáticas y técnicas fruto de motivaciones personales: la psicología individual del personaje y la emoción son importantes para su teatro, porque la preocupación de fondo es el conflicto filosófico ya señalado. En todo caso, esta poética muestra la relación nuevamente conflictiva entre un artista y sus predecesores en términos de angustia (Bloom, 1973).

Retrotraernos contexto de producción teatral de la posguerra, en la cual no sólo Brecht fue una gran influencia, sino también los fueron Beckett, Artaud, el existencialismo de Camus y el Teatro del Absurdo en general nos muestra nuevamente la dificultad en el establecimiento de filiaciones claras y unidireccionales. Esta situación nos sirve para pensar que el teatro de Shaffer se configura a base de técnicas que pueden pertenecer a más de una de estas líneas de influencia, pero que en última instancia 
responden a un proyecto estético personal y no homologable al de sus predecesores y contemporáneos.

\section{A modo de conclusión}

En este trabajo hemos planteado un problema constante de los estudios comparados: la dificultad para establecer filiaciones e influencias sin recaer en simplificaciones orientadas por períodos o movimientos. Lo que el cotejo de la obra de Brecht y Shaffer nos muestra es que existen puntos de contacto en cuanto a las prácticas escénicas y reflexiones sobre los objetivos del hecho teatral, pero las bases filosóficas e ideológicas de ambos resultan irreconciliables. Un análisis que prescinda de estas dimensiones cae en una despolitización de las formas al vaciarlas de significado. El aspecto significativo de las formas y su rol en la construcción de una poética escritural será profundizado seguramente por futuros estudios que den cuenta de la endo y exogénesis, es decir, mostrando la escritura en marcha.

Esta revisión nos permite también volver a la obra de Brecht (tanto teórica como teatral) y observar el modo en que ha sido leída por la historiografía literaria y teatral, cómo se la ha tomado para trazar cartografías, cuya pertinencia puede ser más o menos discutible. En este sentido, Brecht sigue estando por doquier aunque más no sea para discutir con su ideario. Las poéticas teatrales de todo autor se revelan, además, como un territorio desafiante para la intervención del crítico. Delimitarlas supone interrogarse por una serie de asunciones sobre ideas arraigadas como el concepto de influencia. 


\section{Bibliografía}

"Amícola, J. (2004). "1973: el caso Buenos Aires”. Cuadernos hispanoamericanos 644, 7-13.

»Billington, M. (2013, 18 de septiembre). "Bertolt Brecht: irresistible force or forgotten chapter in theatrical history?". En: The Guardian. Consultado el 26 de mayo de 2020 en <https://acortar.link/liSDV>

»Bloom, H. (1973). The Anxiety of Influence. Oxford: Oxford University Press.

»Brecht, B. (1957). Ópera de los dos centavos. Buenos Aires: Losange.

»Brecht, B. (1964). El alma buena de Se-Chuan. Buenos Aires: Ediciones Nueva Visión.

»Brecht, B. (1965). La resistible ascensión de Arturo Ui. Buenos Aires: Ediciones Nueva Visión.

»Brecht, B. (2009). Escritos sobre el teatro. Madrid: Alba.

»Castagnino, H. (1969). Teatro: teorías sobre el arte dramático. Buenos Aires: Centro Editor de América Latina.

»Derrida, J. (1971). Márgenes de la filosofía. Madrid: Cátedra.

»Derrida, J. (2008). “Escritura teatral y escena: el nuevo concepto de texto dramático". Revista Colombiana de las Artes Escénicas, 2 (2), 7 - 18. Consultado el 26 de mayo de 2020 en <https://acortar.link/S367W>

»Dubatti, J. (2003). El convivio teatral: Teoría y práctica de teatro comparado. Buenos Aires: Atuel.

»Dubatti, J. (2013, 26 de junio). “Hacer pagar el dolor del absurdo”. En: Tiempo argentino. Consultado el 26 de mayo de 2020 en <https://acortar.link/Ku1eN>.

"Esslin, M. (1966). “Brecht and the English Theatre”. The Tulane Drama Review, 11 (2), 63-70.

"Esslin, M. (2000). "Brecht and the English Theatre". En: Martin, C. y H. Bial (eds.), Brecht Sourcebook (pp. 145-153). Nueva York: Routledge.

" Gagliardi, L. (2015). “'Un saludo a los fantasmas del futuro’ o cómo leer la temporalidad en Amadeus de Peter Shaffer. Ponencia presentada en el II Congreso de la Delegación Argentina de la Asociación de Lingüística y Filología de América Latina (ALFAL) y VII Jornadas Internacionales de Investigación en Filología y lingüística. La Plata, 21 al 24 de abril de 2015 (en prensa).

"Gagliardi, L. (2016). Risa, noche y escritura. Génesis escritural de Amadeus, de Peter Shaffer (Tesis). La Plata: Universidad Nacional de La Plata.

" Gaspar, M. V. (2003). Influencia de las puestas en escena brechtianas: el ejemplo de E. Bond. (Tesis). Valencia: Universitat de València. Consultado el 26 de mayo de 2020 en <http://roderic.uv.es/handle/10550/15277>

" ílter, S. (2006). The use of Time as an Element of Alienation effect in Peter Shaffer's The Royal Hunt of the Sun, Yonadab, and The Gift of the Gorgon. (Tesis). Ankara: Middle East Technical University.

"Innes, C. (2002). Modern British Drama: The Twentieth Century. Cambridge: Cambridge University Press. 
》Jameson, F. (2013). Brecht y el método. Buenos Aires: Manantial.

»Lai, F. (1989). Peter Shaffer's dramatic vision of the failure of society: a study of The royal hunt of the sun, Equus and Amadeus (Tesis). Burnaby: Simon Fraser University.

» MacMurraugh-Kavanagh, M. (1998). Peter Shaffer: Theatre and Drama. Londres: Mcmillan.

"Mahdi, M. (2014). Shaffer's The Royal Hunt of the Sun and Amadeus: A Creative Representation of History. (Tesis). Beirut: Middle East University. Consultado el 26 de mayo de 2020 en <http://goo.gl/RkdlvZ>

»Marchese, A. y J. Forradelas (2013). Diccionario de retórica, crítica y terminología literaria. Barcelona: Ariel.

" McLane-lles, B. e lles, L. (2007). “1980-Present”. En: Cody, G. H. y Sprinchorn, E. (eds.), The Columbia Encyclopedia of Modern Drama (pp. 413-417). Columbia: Columbia University Press.

»Plunka, G. A. (1988). Peter Shaffer: Roles, Rites, and Rituals in the Theater. Rutherford: Fairleigh Dickenson University Press.

» Reinelt, J. G. (1996). After Brecht. British Epic Theater. Michigan: University of Michigan Press.

» Rodrigo Burón, D. (2013). “El origen del teatro épico. Fundamentos para una práctica revolucionaria". Scientia helmantica. Revista Internacional de Filosofía, 1. Consultado el 26 de mayo de 2020 en https://acortar.link/EfmUH

» Rosenthal, D. (2013). The National Theatre Story. Londres. Bloomsbury.

»Shaffer, P. (1963). The Royal Hunt of the Sun. Londres: Samuel French.

»Shaffer, P. (1973). Equus. Londres: Penguin.

》Shaffer, P. (2001 [1979]). Amadeus. Londres: Harper Perennial.

" The Guardian (1956, 16 de julio). “Europe's most controversial theatre”. En: The Guardian. Consultado el 26 de mayo de 2020 en <https://acortar.link/yubpH>

»Vegas, M. J. y N. Carbonel (1998). Literatura comparada: principios y métodos. Madrid: Gredos.

"Wamba, G. (2013). “El teatro de la nueva objetividad”. Ficha de cátedra. La Plata: Facultad de Humanidades y Ciencias de la Educación. Consultado el 26 de mayo de 2020 en <https://acortar.link/p2bRN>.

»Wellwarth, G. (1966). Teatro de protesta y paradoja. Madrid: Lumen. 